\title{
Redes académicas transnacionales y la física argentina en las décadas de 1940 y $1950^{*}$
}

\author{
Transnational academic networks and Argentinean physics in the decades \\ of 1940 and 1950 \\ Hernán Comastri ${ }^{* *}$ \\ Universidad de Buenos Aires, Buenos Aires, Argentina
}

Recibido: 23 de octubre de 2013. Aprobado: 06 de marzo de 2014.

\begin{abstract}
Resumen
El presente artículo tiene como objetivo describir las consecuencias que la transformación de las redes académicas transnacionales, de mediados del siglo XX, tuvo para un país periférico a las mismas, como lo fue la Argentina de aquella época. Se tomará el caso específico de la física, y se estudiarán dos casos centrales en la institucionalización y modernización de la disciplina en el país: Enrique Gaviola, formado bajo los parámetros de la cultura académica alemana, y José Balseiro, formado en un contexto ya mucho más fuertemente influenciado por la cultura académica anglo-norteamericana y su particular forma de aproximación a la labor científica. El traspaso del centro de dicha red transnacional de Alemania hacia los Estados Unidos, luego de 1945, implicó un proceso de "selección" de la población académica, que también alcanzó a los nodos más alejados del centro, como fue el caso de la Argentina: diferencias culturales sobre la legitimidad y el rol social del científico impidieron una transferencia directa del capital acumulado e invertido en la academia alemana hacia los nuevos centros norteamericanos, y no todos los científicos supieron (o estuvieron dispuestos) a adaptarse a las nuevas condiciones y contextos sociales de trabajo.
\end{abstract}

Palabras claves: redes académicas transnacionales, física, Argentina

Este artículo forma parte de la tesis para optar al grado de doctor: "La política científica en el primer peronismo: discursos e imaginarios sociales (1946-1955)". Programa de Doctorado en Historia, Facultad de Filosofía y Letras, Universidad de Buenos Aires (UBA).

** Universidad de Buenos Aires, Facultad de Filosofía y Letras. Buenos Aires, Argentina. Correo electrónico: hernancomastri@gmail.com 


\begin{abstract}
The present article has the objective of describing the consequences that the transformation of the transnational academic networks of the mid twentieth century had on a peripheral country such as Argentina. The specific case of physics will be presented, as well as two figures that were central to the process of modernization of the discipline in that country: Enrique Gaviola, trained in German academic culture, and José Balseiro, trained in a context much more influenced by Anglo-American academic culture. The movement of the center of such a transnational academic network from Germany to the United States, implied a process of "selection" among the academic population that also reached Argentina: cultural differences over the legitimacy and the social function of the scientist, prevented a direct transfer of the capital accumulated and invested in the German academy to the new American centers, and not all the scientists were able to adapt (or accept) to their new labor conditions and social positions.
\end{abstract}

Keywords: transnational academic networks, physics, Argentina

\title{
Introducción
}

La mayor parte de las biografías de los principales referentes de la ciencia en Argentina han sido realizadas por fuera del ámbito de la historia en tanto disciplina académica y no se ha propuesto, en consecuencia, una mirada crítica hacia sus objetos de estudio. La historia de la ciencia debe sumar a estas crónicas una mayor sustancia teórica y la rigurosidad propia del método historiográfico, recuperando su gran valor en tanto recopilaciones documentales y discursos emitidos desde el interior mismo de los campos disciplinares que se estudian. Esto es una de las tareas que se propone abordar el presente artículo, especialmente en referencia a los trabajos de Mariscotti (2004), Bernaola (2001), López y Bandino (2000).

Estos estudios resultan esenciales para reconstruir las trayectorias profesionales de dos físicos argentinos, que tuvieron un rol central en la historia institucional de su disciplina hacia mediados del siglo XX, y más específicamente durante el primer peronismo. No me concentraré aquí en sus aportes individuales al desarrollo nacional o internacional de la ciencia, sino en la pertenencia de estas dos figuras a distintas redes y culturas académicas, que en el período se disputaron la organización de las investigaciones científicas en el plano internacional. Se han elegido, en última instancia, porque fueron figuras 
centrales en el proceso de organización de la física nacional y porque sirven a modo de ejemplo de las opciones a las que se enfrentaron los académicos de un país periférico como la Argentina, cuando los propios centros científicos internacionales se transformaron, hacia 1945, como consecuencia de la Segunda Guerra Mundial y de procesos de más largo plazo.

Para observar diacrónicamente la composición y características de las redes intelectuales en las que se insertaron, se presentará primero la experiencia de Enrique Gaviola, nacido con el cambio de siglo y relacionado desde la década del 20 con la universidad alemana, sus premios Nobel y sus profesores visitantes en la Argentina. A continuación, trataré de demostrar cómo dichas influencias pueden rastrearse en la posterior actuación profesional de Gaviola, tanto como investigador y como propulsor de diversos proyectos institucionales. Aunque tuvo gran reconocimiento internacional, operó durante un período en el que el centro internacional de la física pasaba de Alemania a los Estados Unidos, proceso que no dejó de tener consecuencias en la periferia de las redes académicas transnacionales. Una de dichas consecuencias fue el surgimiento del Estado como protagonista en la coordinación, financiación y dirección de la investigación científica.

En este sentido, el hecho de que la comunidad científica funcione con criterios transnacionales, no debería hacernos olvidar el peso decisivo que los Estados nacionales tuvieron en la promoción del desarrollo científico y tecnológico. Esto es especialmente cierto para la segunda mitad del siglo XX, y vale tanto para las potencias vencedoras en la Segunda Guerra Mundial como para la Argentina del primer peronismo. La capacidad de adaptación a estas nuevas condiciones de trabajo significó la diferencia entre la (relativa) marginación profesional y el acceso a recursos nunca antes puestos a disposición de la investigación científica. Para observar de qué manera se "negociaron" tales compromisos con el poder político, se recuperará la experiencia de José Balseiro, su intervención en el affaire Richter y su impulso a la creación de un instituto de física permanente en la ciudad de Bariloche.

\section{Enrique Gaviola: formación y contactos en el extranjero}

Gaviola fue una de las figuras centrales en la renovación de la física en el país a partir de la década de 1930, gracias a su capacidad para actuar como vehículo para la apropiación local de las experiencias y teorías innovadoras que se desarrollaban en los centros internacionales de su disciplina. Y, también, gracias a su actividad tendiente a traducir dichos cambios en la creación de instituciones que les ofrecieran continuidad en 
el tiempo. La combinación de estas dos características ubicó a Gaviola en el centro de una red de contactos académicos y científicos que conectó diversas instituciones argentinas y extranjeras durante las décadas de 1940 y 1950.

Nació en 1900 en Mendoza, donde completó sus estudios primarios y secundarios. Su primer acercamiento a la física, sin embargo, sucedió en la carrera de Ingeniería de la Universidad Nacional de La Plata (UNLP), donde tuvo como profesor y fue profundamente influenciado por el alemán Richard Gans. No existiendo aún un claro campo de estudio para la física en la Argentina, Gaviola cambió de carrera pero permaneció en La Plata, y para 1921 ya contaba con el título de agrimensor emitido por la UNLP. Como le gustaba recordar, se hubiera recibido un año antes de no haber sido por "la famosa reforma universitaria", que él igualaba a la demagogia y el desgobierno de la universidad (Gaviola, 1931). De todas maneras, estas apreciaciones no son contemporáneas a los hechos referidos, sino que fueron realizadas con más de una década de distancia, y se encuentran mediadas por su experiencia (experiencia formativa, según intentaré argumentar) en Alemania. En este sentido, su crítica al ideario reformista no debe interpretarse como una defensa de la formación escolástica, característica de la universidad argentina anterior a 1918, sino más bien como el rechazo a sus intenciones democratizantes frente a lo que él consideraba un orden jerárquico "natural", basada en el mérito personal y la cultura.

Su padre, don Modesto Gaviola, había sido el jefe político del Departamento de Rivadavia, Mendoza, por largos años. Así lo recordaba: "De mi padre aprendí que ser aristócrata, aunque sea pequeño aristócrata de pueblo rural, significa tener iguales derechos pero mayores deberes que los demás. Y que sin una aristocracia responsable y desapegada la democracia fracasa" (Gaviola, 1965, p. 1). Esta posición, si bien en 1920 era contraria al movimiento académico de su generación, no era contradictoria respecto a los modelos de la época en lo que se refería a la actividad científica. El sistema de educación superior y el sistema social de la ciencia, en este sentido, deben ser entendidos como sistemas de función relacionados entre sí, pero en última instancia diferentes y autónomos en lo que respecta a sus objetivos, formas de organización y representación (Stichweh, 2006, p. 276).

A diferencia de lo que ocurría en el sistema de la educación superior, por ejemplo, para la incipiente comunidad de científicos argentinos el modelo a seguir era, generalmente, el alemán. Esto era particularmente claro en el ámbito de las ciencias exactas y naturales, y más específicamente en la física. Lo anterior puede explicarse, en parte, por el liderazgo internacional de la ciencia alemana de la época y en parte por la larga tradición de profesores de dicha nacionalidad que visitaban las universidades argentinas 
y actuaban como vehículo para el desarrollo local de nuevos campos de estudio, o la renovación de otros que habían quedado desactualizados respecto a los últimos avances en los centros científicos internacionales ${ }^{1}$. Los viajes de argentinos que realizaban estudios en Alemania terminaron de cimentar esta relación transnacional y difundir la cultura e ideología académica alemana en el país. Tal fue el caso de Gaviola.

Su título de agrimensor había sido apenas un primer acercamiento a la física y el medio a través del cual pudo ahorrar el suficiente dinero para, en 1922, embarcarse hacia Alemania, donde continuaría sus estudios entre los más destacados científicos de la época. Llevaba consigo una carta de recomendación de Gans que le abrió las puertas de la Universidad de Göttingen; sus propias inquietudes lo llevarían más tarde a la Universidad de Berlín y a la Universidad Georg Auguft, en la misma ciudad, donde recibiría su título de doctor en Física en 1926. En esos breves cuatro años tuvo como profesores a cinco premios Nobel, dos de los cuales aceptaron apadrinar su tesis final (Bernaola, 2001, pp. 164 y 165).

En Göttingen había tres institutos de física: el dirigido por Robert Pohl (a quien iba dirigida la carta de Gans), el de James Franck y el de Max Born. Gaviola cursó materias y seminarios en los tres, pero su trabajo experimental causó una impresión particularmente buena en Franck, quien por cuenta propia envió una carta a su colega Peter Pringsheim, en Berlín, cuando Gaviola pidió el traslado a dicha ciudad. Gracias a esta nueva recomendación, aquellos años de estudio fueron también acompañados por un fructífero trabajo de investigación bajo la dirección de Pringsheim y los primeros papers de Gaviola en una revista de circulación y prestigio internacional como era Zeitschrift für Physik.

De acuerdo a las reglamentaciones de la universidad alemana, antes de que un estudiante pudiera comenzar su tesis, debía haber aprobado el llamado preseminario, en el cual era evaluado sobre un tema de actualidad científica. El jurado que escuchó a Gaviola estaba compuesto por Pringsheim, Max von Laue (Premio Nobel de Física en 1914), Lise Meitner y Albert Einstein (Premio Nobel de Física en 1921); aprobó el mismo en 1924 y en 1926 entregó su tesis, que le valió la calificación Magna cum laude.

1. Como reflejo de dicho liderazgo pueden citarse los premios Nobel otorgados en Física y Química entre 1901 (año en que se entregaron por primera vez) y 1939 (año en que comenzó la Segunda Guerra Mundial): Alemania cuenta con 26 premios, Inglaterra con 19, Francia con 12 y Estados Unidos apenas con 7. Con la derrota alemana en la guerra, este predominio alemán comenzó a revertirse. 
Completados sus estudios en Alemania, Gaviola buscó continuar su trabajo en los Estados Unidos. En una carta escrita a Juan José Nissen apenas dos años después, explicaba de la siguiente manera su decisión: "Mi ida a EUA fue dictada por la necesidad de hacerme conocer allí, para tener un lugar de refugio cuando necesidades estratégicas me llevaran a abandonar temporalmente el país" (Bernaola, 2001, p. 173). Este razonamiento, llamativo en más de un sentido, da cuenta tanto de la pertenencia a una comunidad de carácter transnacional pero con centros muy bien definidos, como de la importancia de lo nacional. La correspondencia de Gaviola repite esta idea de forma casi obsesiva: la formación en los principales centros científicos internacionales era considerada un medio de adquirir las "credenciales" suficientes para asegurarse una posición en la Argentina o, en su defecto, funcionaba como una alternativa (temporal) frente a posibles coyunturas adversas a los proyectos que tenía para la organización de las investigaciones científicas en el país.

Para poder viajar a los Estados Unidos, Gaviola se presentó a una convocatoria abierta por la International Board of Education, pero a pesar de haber obtenido la calificación más alta entre todos los candidatos, su solicitud fue rechazada porque, por cuestiones administrativas, solo podían ser aceptados ciudadanos norteamericanos o europeos. Nuevamente, fue necesaria la intervención de sus contactos personales, esta vez en la forma de una carta de Einstein, para que se hiciera efectiva aquella primera fellowship otorgada a un científico del hemisferio sur.

\section{La ciencia misionera: el regreso de Gaviola a la Argentina}

La intención de regresar al país a pesar de las permanentes ofertas de universidades norteamericanas, e impulsar aquí un profundo cambio en la organización de la universidad y el incipiente sistema científico, estuvo siempre presente en su correspondencia

y respondía a un rasgo idiosincrático que no puede resumirse en una mera característica individual, en tanto posee un componente social y se ajusta a un ethos típico de la época y del medio en el que Gaviola se formó como científico. Moulin (2006), en su estudio sobre el Instituto Pasteur, describe este ethos al caracterizar lo que ella llama el "científico misionero" de corte pastoriano.

Si bien ella se concentra en el caso francés y utiliza esta conceptualización para la ciencia colonial de fines del siglo XIX, sería plausible pensar que dicho modelo de comportamiento haya sobrevivido a sus condiciones específicas de surgimiento, en especial en la interacción entre centro y periferia. Considero que el ideal pastoriano, en tanto 
modelo de comportamiento, responde a rasgos culturales más amplios que podrían generalizarse al conjunto de las potencias europeas de fines del siglo XIX. En lo que respecta a las "culturas académicas" nacionales (que se tratarán más adelante), Harwood realiza una operación similar al señalar las similitudes entre la Bildungstradition alemana y el concepto francés de culture generale como bases de una común forma de intervención del científico en la sociedad, la política y la cultura nacional ${ }^{2}$.

Ahora bien, si la autora evalúa la llamada "ciencia misionera" como "un caso claro de imperialismo cultural", no es solo porque la misma hundía sus raíces en una política colonial (de por sí común a todas las potencias europeas, justificando así una ampliación desde la experiencia francesa hacia el conjunto europeo), sino también, y principalmente, por las relaciones asimétricas que se establecen entre los distintos puntos de la red transnacional que la misma construye y busca perpetuar. $Y$ es en este punto donde dicha caracterización podría relacionarse con la figura de Gaviola. La defensa de la "universalidad" de la ciencia moderna no es incompatible, sino que se combina con la competencia internacional por fijar sus objetivos, reglas, límites y formas de organización desde diversos centros nacionales con aspiraciones de hegemonía o influencia económico-cultural. Y los nodos periféricos de esas redes participan del esfuerzo por expandir la influencia y el liderazgo intelectual de los centros, bajo cuyos parámetros se han formado y en los que han acumulado e invertido su capital intelectual.

Es por esto que el "científico misionero" no debe necesariamente provenir de Europa para actuar como difusor de sus valores. Lo que lo distingue, en cambio, es el convencimiento de imponer la ciencia como práctica civilizadora sobre los países atrasados. Ciencia universal, pero cuyos contornos han sido reconocidos en una nación/metrópolis que a partir de entonces será tomada como modelo de desarrollo para la periferia. $\mathrm{Si}$ "Pasteur estaba convencido de que la ciencia no tenía patria y de que los científicos debían ser devotos de sus propios países, en igual medida" (Moulin, 2006, p. 120), esto vale tanto para los científicos provenientes de los centros de la ciencia internacional que buscan ampliar la influencia económico-cultural de su nación, como para aquellos provenientes de la periferia, que buscan las herramientas para el desarrollo económico y cultural de sus países de origen.

2 Harwood señala este parecido para reconocer que las culturas académicas por él descritas pueden, de hecho, englobar conjuntos mucho más amplios que los estados nacionales en los que él ha encontrado su expresión más clara. Así, la cultura académica alemana puede en ocasiones identificarse con una cultura académica centroeuropea, o aún con una cultura académica continental europea más general (2006, pp. 50 y 69). 
Las iniciativas reformistas de Gaviola respecto a la universidad argentina pueden rastrearse, como ya se ha mencionado, hasta el mismo proceso de la Reforma del 18. Ya en Alemania, y en vísperas del viaje que Albert Einstein realizaría a Brasil, Argentina y Uruguay en 1925, Gaviola le acercó a este último un borrador de aquel "manifiesto" que finalmente publicaría en 1931. Su intención era que Einstein, ya en ese momento una figura de renombre internacional no solo en ámbitos académicos, pudiera poner su nombre detrás de las propuestas de modernización de la universidad argentina, que tomaban como modelo los institutos universitarios alemanes. Finalmente, los diarios argentinos publicaron una nota titulada La opinión del sabio Einstein con los puntos de vista y consejos del físico alemán sobre la situación universitaria en Argentina, aunque la misma difería en varios puntos del manifiesto elaborado por Gaviola (De Asúa y Hurtado, 2006, pp. 101-115).

Más adelante, se mencionarán otras dos intervenciones del físico argentino, que tuvieron como objetivo impulsar nuevas formas de organización para la universidad argentina.

Yendo de lo más amplio a lo más acotado, mencionaré a continuación los cambios impulsados por Gaviola en la cátedra de la que se hizo cargo en 1929 en la UNLP:

La aceptación de Gaviola del ofrecimiento en la FCEFN [Facultad de Ciencias Exactas, Físicas y Naturales de la UNLP] fue muy particular. No se presentó, como es habitual en estos casos, para recibir directivas sobre el trabajo que debía realizar. Por el contrario, mucho antes de su nombramiento, el 30 de mayo de 1930, había elevado un memorándum sobre la orientación que daría al curso de Fisicoquímica "en caso de que se me encargara el mismo". (...) Pretendía, además, que los asistentes que se le asignaran se adaptasen a su modalidad de enseñanza. En el nuevo cargo y debido a su insistencia, Gaviola logró dictar, por primera vez, electromagnetismo, termodinámica de la radiación, teoría cinética y teoría cuántica, que hasta entonces no figuraban en el plan de estudios. Logró, también, que el 2 de junio de 1930 la biblioteca se suscribiera a 16 revistas de investigación y que el 14 de octubre se creara el curso de manipulación de vidrio (Bernaola, 2001, p. 184).

Cito en extenso este fragmento del libro de Bernaola porque ilustra bien tanto el proyecto de modernización de Gaviola, como el reconocimiento de la institución al capital académico acumulado por el joven físico en los centros científicos de Alemania y Estados Unidos. 
Su regreso al país fue propiciado por las autoridades de la universidad, como una forma de ocupar el vacío producido por el alejamiento de Gans en 1925. Pero lo ambicioso de los proyectos de renovación disciplinar propulsados por Gaviola, y no siempre apoyados por la institución, provocaron que ya en 1933 elevara su renuncia para pasar el siguiente año, becado por el gobierno español, en el Instituto Nacional de Física y Química del Instituto Rockefeller de Madrid. Terminado su trabajo allí, fue contactado por el director del Consejo de Observatorios de la Argentina, Félix Aguilar, para supervisar la terminación de los trabajos del gran espejo del Observatorio Astronómico de Córdoba $(\mathrm{OAC})$, que llevaba décadas de atraso y había arrastrado a la institución entera a un largo período de decadencia.

Para abocarse de lleno a dicha cuestión, Gaviola reorientó los objetivos de la beca que en 1935 le había otorgado la John Simon Guggenheim Memorial Foundation, originalmente para trabajar en fisicoquímica con Carl Linus Pauling (Nobel en 1954). En cambio, pasó los próximos 13 meses en el California Institute of Technology (CALTECH) y en el Mount Wilson Observatory, también en California. Su relación con el OAC continuaría en años posteriores con la supervisión de los trabajos finales sobre el gran espejo y su transporte desde Estados Unidos, luego como astrofísico y vicedirector (entre 1937 y 1940, bajo la gestión de su colega Juan José Nissen, primer astrofísico argentino en dirigir el observatorio cordobés) y, finalmente, como director del mismo entre los años 1940 y 1947.

Durante este último período, el OAC tuvo un funcionamiento destacado, que se potenció con la contratación del exiliado europeo Guido Beck para el dictado de los cursos de física teórica en 1943. El observatorio pasó, así, a convertirse en el centro de investigación y formación superior en física más influyente del país, pero manteniéndose al margen de la masividad, la política y los conflictos propios de la universidad. En este rol de formador de nuevas generaciones de físicos argentinos, Gaviola pronto se convirtió en una figura capaz de liderar el proceso de institucionalización de una disciplina que se renovaba y crecía a ritmo acelerado. En 1945, también en Córdoba, nacía la Asociación Física Argentina (AFA) a partir de las reuniones anuales que, desde 1942, había mantenido el llamado "Núcleo de Física Teórica", promovido por Gaviola y Beck.

Esta última iniciativa de carácter nacional (que sobrevive hasta hoy) terminó de consolidar la extensa red académica que Gaviola había sabido tejer en el exterior, y respecto de la cual se había convertido en un intermediario obligado. Pero lo hizo, sin embargo, en una época en la que se experimentaba un corrimiento de los centros científicos 
a nivel internacional, que tendría consecuencias sobre la forma de hacer ciencia también en Argentina.

\section{Culturas académicas y Big Science: transformaciones de la posguerra}

En oposición a un sentido común construido en torno a las ciencias naturales (en parte, como consecuencia de su propia autorrepresentación), las mismas están lejos de ser una lingua franca internacional. Estas disciplinas son, de hecho, influenciadas por sus contextos socio-culturales, sus orígenes nacionales y los objetivos político-económicos que persiguen en sentido amplio (Bloor, 1998). El estudio ya citado de Harwood ofrece un excelente ejemplo de dichas influencias, al describir en detalle las diferencias entre las culturas académicas de Alemania y los Estados Unidos durante el período de entreguerras. El análisis de las características divergentes de cada cultura cobra especial importancia si se tiene en cuenta que, una antes y otra después de la Segunda Guerra Mundial, aquellas fueron las culturas internacionalmente dominantes en el área de las ciencias exactas y naturales.

El corrimiento del centro científico internacional está determinado por el resultado de la guerra misma, pero no de forma exclusiva. De hecho, ya a partir de 1918 los alemanes hablaban de un proceso de "americanización" de la República de Weimar en referencia al supuesto declive cultural hacia una civilización pragmática y materialista. La velocidad del cambio tecnológico, las transformaciones de la moderna sociedad industrial y el nuevo rol del Estado en relación a las mismas, hicieron de la aproximación anglo-estadounidense a la ciencia un modelo más compatible con el mundo de la Guerra Fría, que aquel que tradicionalmente había impulsado Alemania. La cultura académica promovida por aquel país se había caracterizado por una amplia erudición, el respeto a la cultura humanista y un especial interés en los desarrollos teóricos de la llamada "ciencia pura”.

El aumento del presupuesto apuntado a ciencia registrado en las últimas décadas del siglo XIX, se había traducido en nuevos recursos para las instituciones científicas y académicas ya existentes, por lo que reforzó las formas de organización y jerarquías heredadas, así como la necesidad de una amplia erudición por parte de aquellas personas que se encontraban al frente de institutos cada vez más grandes y diversos. Algo similar ocurría con aquellas personas que pretendían hacer carrera en un sistema que ofrecía pocas posibilidades de ascenso al interior de cada instituto y que, por lo tanto, diversificaban 
sus intereses académicos y sus líneas de investigación para poder aprovechar eventuales oportunidades en otros institutos.

Pero la amplia formación humanista presente en el profesorado alemán respondía también a su evaluación de los cambios sociales experimentados por la industrialización y la modernización del país. En este sentido, se señalaban la "patología social urbana" y el "malestar político" como productos de una crisis de valores de la nación, a la que el mundo académico debería responder a través de la construcción de una nueva visión unitaria, capaz de forjar un conjunto solidario a partir del mundo moderno.

Durante y después de la guerra, la principal diferencia que destacaban tanto los emigrados alemanes como sus anfitriones norteamericanos, fue la amplitud de la erudición de los primeros frente a la intensa especialización de los segundos, así como la falta de respeto que los mismos otorgaban a la cultura humanista. Allí donde los alemanes se sentían más cómodos con la teoría, los estadounidenses preferían la empiria. Por supuesto, los norteamericanos no ignoraban el trabajo teórico, pero entendían que el mismo debía estar apuntado a la predicción antes que a la ontología, rechazando así la distinción entre ciencia "pura" y aplicada.

Mientras que entre 1870 y 1914 el aumento del presupuesto alemán destinado a la investigación científica se había repartido entre instituciones ya existentes, en Estados Unidos se propició un aumento en el número de los espacios de investigación, favoreciendo la institucionalización de nuevos campos y la consolidación del sistema de departamentos de trabajo colectivo, en lugar del sistema alemán de institutos dirigidos por un solo profesor, el único, de hecho, que contaba con la titularidad de su cargo.

A esta caracterización, que sigue las líneas de lo señalado por Harwood, se puede agregar un conjunto de rasgos que dicho autor deja fuera de análisis y que son específicos de la cultura académica norteamericana en la década que sigue al fin de la Segunda Guerra Mundial, especialmente en lo que respecta al rol social y político del científico. Para ello, resulta de esencial importancia el trabajo de Reisch (2009).

Disciplinas aisladas, extremadamente especializadas y despolitizadas son la herencia de la década de 1950. Nociones externas al campo científico (la "seguridad nacional", la "infiltración comunista", la defensa a ultranza de valores absolutos como "patria" y "libertad") sirvieron al Estado para silenciar discusiones que, desde la especificidad y la legitimidad del mundo académico, antes habían interpelado a toda la sociedad. Bajo el peso de investigaciones y persecuciones de los servicios de inteligencia, diferencias inte- 
lectuales en torno a la cultura y la política fueron transformadas en diferencias de lealtad nacional.

Inmersos en una sociedad mayormente antiintelectual, los científicos aceptaron su creciente aislamiento a cambio de los beneficios del nuevo patrocinio estatal de la ciencia y un gran margen de autonomía hacia el interior de su disciplina. En otras palabras, abandonaban progresivamente el rol del intelectual por el del experto ${ }^{3}$.

Pero los cambios en la organización de la comunidad científica que acompañaron el corrimiento del centro científico internacional de Alemania hacia los Estados Unidos, no se acotaron solo al ámbito de las culturas académicas, sino que respondieron a condiciones materiales nuevas. En 1945, el ingeniero Vannevar Bush, asesor del presidente Truman para el área científica, le entregaba a este un memorándum titulado Science, The Endless Frontier, en el que defendía el mantenimiento de la inversión pública en investigación básica y aplicada una vez finalizada la guerra, sosteniendo en épocas de paz un presupuesto multiplicado como consecuencia del esfuerzo bélico. El documento anunciaba una nueva época de patrocinio estatal (y en la mayoría de los casos, militar) acorde a las necesidades de la naciente Big Science (Weinberg, 1961).

El presupuesto de los Estados Unidos dedicado a la investigación científica, de 97 millones de dólares en 1940, se multiplicó hasta alcanzar los 1.600 millones en 1945 (Feld y Hurtado, 2010). Aunque a un menor ritmo, estas inversiones siguieron aumentando en los años de la posguerra. A cambio, el gobierno federal y las Fuerzas Armadas aumentaron proporcionalmente su injerencia y control sobre las líneas de investigación y desarrollo que debían ser consideradas prioritarias, privilegiando en primer término el área de Defensa. Una nueva forma de ciencia transnacional se expandía por el globo, pero si los cambios en el rol del Estado norteamericano influyeron en el conjunto de la red, esto no fue únicamente por las consecuencias que las nuevas formas de organización institucional tuvieron sobre la comunidad académica que trabajaba en los Estados Unidos, sino también porque diversos Estados de la periferia comenzaron a imitar el ejemplo norteamericano y del conjunto de las potencias involucradas en la última guerra mundial.

En Argentina, los gobiernos de facto de los militares del GOU y las primeras presidencias de Juan Domingo Perón no fueron la excepción. Así, entre 1943 y 1955, el Estado

3 Mientras que el intelectual dreyfussiano supone un individuo legitimado en sus intervenciones públicas por una forma de pensamiento crítico, independiente y apoyado en la razón y los valores universales, el experto se generaliza con la segunda posguerra como especialista técnico que trabaja en y para el Estado. Para más detalles ver Neiburg y Plotkin (2004). 
aumentó significativamente los recursos volcados en el área, le otorgó un rol protagónico a las Fuerzas Armadas y buscó establecer una mayor coordinación y control (tanto profesional como político-ideológico) sobre la comunidad académica, control que en el caso argentino incluyó una intervención mucho más abierta y disruptiva sobre los espacios de autonomía construidos por dicha comunidad. El mayor presupuesto se tradujo en nuevas instituciones y nuevas líneas de investigación, que buscaron compatibilizarse con planificaciones socio-económicas de mayor alcance, como aquellas de los planes quinquenales peronistas. Por último, el contexto específico de la inmediata posguerra permitió al país entrar en la competencia por el acceso a valiosos recursos humanos pertenecientes a las antiguas naciones del Eje, en ese momento incapaces de sostener su anterior infraestructura académica y de investigación.

A los problemas propios del cierre de la brecha científico-tecnológica que separa a los países periféricos de los centrales, debe sumarse, además, el costo de adaptarse a una nueva cultura académica dominante. Como trataré de demostrar en el siguiente apartado, tal transición no implica simplemente un cambio en el destino de los viajes de capacitación o en la nacionalidad de los profesores visitantes. En tanto cada cultura académica organiza su propio sistema (si bien no completamente cerrado) de valoración, legitimación y reconocimiento, el capital intelectual acumulado en una red científica que tenía como centro a Alemania, no podía trasladarse sin conflictos a una nueva red con centro en los Estados Unidos y organizada bajo sus parámetros específicos.

\section{Gaviola en el contexto del primer peronismo}

Volviendo al caso de Gaviola, además de la extensa red de contactos ya descrita, su estancia en Alemania terminó de consolidar en él una cultura académica propia de dicho medio. Y digo que tal experiencia "consolidó" dicha cultura académica, porque no fue en este viaje donde entró en contacto con ella por primera vez. El incipiente sistema científico local había sido moldeado en buena medida bajo el patrón de esta cultura, que no debería erróneamente ser acotada solo al caso nacional alemán. De hecho, el sistema científico alemán era el centro de una extensa red de instituciones e investigadores particulares que trascendía las fronteras políticas, y que incluía, si bien en una posición claramente periférica, a un número de científicos argentinos.

Viajes y estadías académicas como los de Gaviola implicaban, no solo un "rito de pasaje" para el individuo que viajaba, sino también una forma de acortar las distancias entre estas unidades tan heterogéneas, de mantener ligados dos puntos que de otra forma 
permanecerían inconexos (Ortiz, 1998, p. 31). Esta fuente de experiencia personal, sin embargo, también conllevaba una reinterpretación de la posición originaria del individuo y de su función en el contexto de su sociedad de origen, como ya se ha observado al proponer el ethos del "científico misionero" como clave de lectura de las intervenciones públicas de Gaviola. A causa de esto, los proyectos reformistas impulsados por él continuarían estando vinculados con la cultura académica alemana, aun cuando dicha cultura ya no fuese la dominante a nivel internacional.

Así, persiste en la base de todas las intervenciones públicas de Gaviola, un sobredimensionamiento de la posición social del científico como agente e ideólogo del cambio social, que no acepta interlocutores legítimos por fuera de los otros miembros de la comunidad científica a la que él pertenecía, de la que representaba el mayor exponente de la Argentina y, por lo tanto, el más indicado para liderar un proceso de modernización de la ciencia nacional. En su correspondencia personal, hoy reunida en el archivo de la Biblioteca Leo Falicov del Instituto Balseiro, hay numerosas fuentes que podrían ser citadas a fin de sostener dicha afirmación; he seleccionado la siguiente a modo de ejemplo:

Pienso quedarme en los EUA hasta que me llamen de aquí, o hasta siempre si no me llaman. Pasaría los cuatro meses de vacaciones en Alemania. Ese es el plan; pero para que me llamen y me den carta blanca, de hacer y deshacer, es necesario que la self propaganda continúe todo el tiempo que esté afuera. Eso se conseguiría mandándole un articulito a un diario para que éste se ocupe de uno. Mi plan inmediato, es escribir una serie de seis o siete artículos sobre nuestras universidades y nuestros problemas culturales y políticos (Bernaola, 2001, p. 174).

La idea de esta "carta blanca, de hacer y deshacer", da cuenta de la concepción que Gaviola tenía sobre el lugar del científico en la sociedad, y los "seis o siete artículos sobre nuestras universidades y nuestros problemas culturales y políticos" (que de hecho escribió), del valor por él otorgado a la erudición y la intervención en la arena pública como medios para acceder al reconocimiento político y social que haría posible la esperada "carta blanca". Esta ambición demostraría en más de una ocasión ser desmedida: en un primer momento debido al lugar marginal que la ciencia ocupaba en las preocupaciones socio-políticas de la Argentina de la década de 1930, y en una segunda instancia, porque a medida que los diversos agentes involucrados en la investigación científica tomaron conciencia de su creciente importancia, la inversión en desarrollos científicos y tecnológicos se hizo bajo el nuevo patrón norteamericano. 
Esto puede constatarse en los diversos intentos de Gaviola por impulsar un organismo con apoyo estatal, que centralizara el fomento a la investigación mediante becas de perfeccionamiento en el exterior y la contratación de investigadores full time. Durante los gobiernos peronistas, la creación de un organismo de dichas características se discutió en varias oportunidades en el recinto del Congreso Nacional y, finalmente, en 1951 y 1953, se concretó en la forma del Consejo Nacional de Investigaciones Científicas y Técnicas (CNICyT) y la Dirección Nacional de Investigaciones Científicas y Técnicas (DNICyT), respectivamente. Sin embargo, la intervención de Gaviola en las discusiones parlamentarias de 1946 solo había tenido por objeto el boicot de un proyecto al que él mismo había ayudado a dar forma, por considerar que el mismo no podía quedar bajo la órbita del Ministerio de Guerra (Mariscotti, 2004, pp. 60-66). El problema, entonces, no era solo de formas, como parece ser la impresión de muchos de los contemporáneos de Gaviola, que lamentaban su falta de la "cintura política" suficiente para llevar sus iniciativas a buen puerto.

El objetivo explícito para la creación del CNICyT y la DNICyT distaba mucho de coincidir con el ideal de Gaviola. Lejos de quedar bajo la dirección de aquella suerte de "aristocracia letrada" que el físico argentino creía reconocer en el profesorado de tipo alemán, la institucionalización de las investigaciones científicas y técnicas quedó supeditada a las necesidades y los planes del Estado, y en consecuencia, bajo la dirección de este. En consonancia con las nuevas tendencias internacionales antes mencionadas, las áreas consideradas prioritarias fueron las relacionadas con la defensa y el desarrollo industrial: sus primeras medidas efectivas estuvieron enfocadas en el problema de la productividad y no, como deseaba Gaviola, en la formación de investigadores en ciencias básicas.

Motivos similares llevaron al gobierno peronista a reducir el presupuesto del OAC, lo que en consecuencia llevó a la renuncia de Gaviola a la dirección del mismo. Las investigaciones que este último promovió durante su gestión del observatorio, no buscaron ningún tipo de vinculación con la planificación socio-económica del gobierno, y el peronismo no estaba dispuesto a financiar "ciencia pura".

Una preocupación en la que sí coincidieron las políticas gubernamentales del primer peronismo con los proyectos de modernización científica de Gaviola, fue respecto a la cooptación de especialistas extranjeros, y especialmente alemanes, en el contexto de la inmediata posguerra. La red de contactos y relaciones (tanto personales como institucionales) en la que el físico argentino se había insertado, lo ubicaba en una posición privilegiada para actuar como mediador entre el Estado argentino y el significativo número de científicos europeos que buscaban oportunidades de trabajo e investigación fuera de un 
continente devastado por la guerra. Como ya había sucedido en el caso de Beck, Gaviola buscó promover la radicación en Argentina de diversos referentes de la física internacional, tanto como una forma de ofrecer refugio y oportunidades de investigación a sus colegas extranjeros, como para promover el desarrollo de la ciencia en el país.

Sin embargo, con el fin de la guerra y la ocupación del continente europeo por parte de las potencias aliadas, el reconocimiento y los contactos académicos dejaron de ser condición suficiente para que dichas migraciones se concretaran. De hecho, los Estados Unidos e Inglaterra (así como, del otro lado de la Cortina de Hierro, la Unión Soviética) cuidaron muy celosamente su monopolio sobre ese particular botín de guerra que representaron los investigadores, planos y prototipos de la ciencia alemana. Y contaban, para tal fin, con el poder de facto de otorgar o denegar los permisos de viaje de cualquier ciudadano alemán que tratara de abandonar su país.

Ejemplo de esto fue el intento argentino de contratar a Werner Heisenberg (Premio Nobel de Física en 1932) para hacerse cargo de un nuevo Instituto Radiotécnico, en el que cooperaron la Marina y Gaviola en representación de la AFA. El cargo y la remuneración fueron suficientes para que, en 1946, Heisenberg aceptara la invitación que Gaviola le había extendido a través de Beck, su antiguo asistente. Sin embargo, el premio nobel alemán se encontraba bajo jurisdicción inglesa, y bastó el simple trámite administrativo de negarle la visa de salida de Alemania para dar por tierra con el proyecto. Aún en tiempos de paz, la comunidad científica transnacional no volvería a gozar de la libertad de acción y de movimiento que, si bien también entonces relativa, había usufructuado hasta el período de entreguerras.

Esto no significa que en el período la ciencia quede acotada al único ámbito de lo nacional; el hecho de que los Estados nacionales ganaran protagonismo en la organización de las actividades científicas, no implicó que la cooperación, intercambio e identidad entre redes científicas transnacionales quedara anulada, sino más bien que en las mismas, el Estado intervenía con una fuerza renovada. En términos prácticos, un país periférico como la Argentina podía buscar acrecentar su peso relativo al interior de dicha red, pero no sin una intervención activa del Estado. Esta intervención podía abarcar (y de forma no excluyente) desde la simple negociación diplomática, como en el caso brasileño, hasta una consistente política de equipamiento y cooptación de recursos humanos, mediante

4 Si bien el secreto militar se convirtió en una constante en los trabajos en física durante la Guerra Fría, y los intercambios académicos se restringieron siempre que los intereses de la "defensa nacional" se veían involucrados, el caso de Heisenberg resulta ejemplar. De hecho, había estado a cargo de uno de los programas atómicos de la Alemania nazi. Sobre este último punto, ver Bellocopitow (2003, p. 24). 
la falsificación de documentos y la triangulación de operaciones fuera del país, como en el caso de la Argentina frente al boicot norteamericano (Comastri, 2012).

Por otra parte, la necesidad de la participación del Estado en la planificación científica en esta nueva etapa se constata no solo en las magnitudes de los presupuestos destinados a la investigación, sino también en la debilidad estructural del empresariado industrial argentino de mediados del siglo XX. El reconocimiento social en tanto "hombre de ciencia” perseguido, y de hecho alcanzado por Gaviola, le permitió desempeñarse como asesor físico, primero en las cristalerías Rigolleau (1947-1951), y luego en General Electric (1952-1956), mientras los desencuentros con el gobierno peronista lo mantenían alejado de las aulas universitarias y los institutos de investigación. Pero no fue suficiente para lograr de estos y otros empresarios una relación de cooperación estable con la AFA, ni la movilización de los recursos precisos provenientes de la filantropía para su proyecto de construir una universidad de investigación privada, que desde 1946 impulsó junto a Eduardo Braun Menéndez, Bernardo Houssay y otros destacados científicos argentinos (Mariscotti, 2004, pp. 42-46).

El caso de Balseiro, tal vez menos destacado desde el punto de vista del prestigio internacional, ofrece sin embargo, un contrapunto a la figura de Gaviola en términos de adaptación al nuevo contexto nacional e internacional.

\section{Balseiro y la autonomía negociada}

José Antonio Balseiro nació en Córdoba en 1919. De la Universidad Nacional de Córdoba consiguió una beca para estudiar Física en la UNLP, carrera de la que egresó en 1944 con una tesis de tipo experimental. Los cambios que mientras tanto había impulsado Gaviola en el OAC, le permitieron volver a su ciudad natal para continuar sus estudios postdoctorales en el observatorio, bajo la dirección de Beck. En 1947, Balseiro volvió a la UNLP para hacerse cargo del dictado de dos materias, pero pronto comenzó sus gestiones para continuar su formación en el exterior. Luego de tres años y varios intentos (entre los que se cuenta una beca otorgada, pero nunca efectivizada, por la Asociación Argentina para el Progreso de las Ciencias), en 1950 consiguió una muy reducida beca del Consejo Británico y se embarcó rumbo a Manchester ${ }^{5}$.

5 La Universidad de Manchester era, en ese momento, uno de los centros más importantes a los que podía tener acceso un argentino, dadas las condiciones impuestas por la posguerra en Alemania y la política de los Estados Unidos de no otorgar becas a físicos extranjeros, por el miedo a la divulgación de secretos nucleares en pleno desarrollo de la Guerra Fría. 
En Inglaterra, Balseiro trabajó en el grupo del físico belga León Rosenfeld. Pero su trabajo en Manchester estaba aún inconcluso y todavía le restaban algunos meses en su beca, cuando recibió un llamado urgente de la embajada argentina en Londres. Corría el año 1952, en Buenos Aires se comenzaba a sospechar de los anuncios de fusión controlada de Ronald Richter y el gobierno de Perón se había decidido a enviar una Comisión Investigadora a los laboratorios de la isla Huemul' ${ }^{6}$. La elección de Balseiro, un joven de 33 años, como integrante de dicha comisión, respondía a una relación previa que es importante reconstruir.

A pesar de que las preferencias o posturas políticas de Balseiro no nos son conocidas, sí es posible afirmar que se relacionó en buenos términos con algunos funcionarios y dirigentes peronistas, aun si, como se desprende de algunas de sus cartas, se encontraba lejos de ser un partidario del gobierno. Las primeras relaciones que he podido rastrear datan de la época que Balseiro pasó como docente en La Plata. De profunda fe católica y siempre interesado por los debates filosóficos, asistió regularmente al Seminario de San José donde, además de participar en las discusiones, dictaba clases de física a los seminaristas. Ya había acudido al mismo durante su época de estudiante en la UNLP, pero ahora también participaban en estas reuniones diversas figuras del peronismo con las que Balseiro entró en contacto, entre ellas Emilio Mignone, director general de Educación de la Provincia de Buenos Aires durante el gobierno de Domingo Mercante, y Arturo Enrique Sampay, ministro de gobierno en el mismo gabinete y uno de los redactores de la Constitución Nacional de 1949 (López y Badino, 2000, p. 104). Si bien esto de ninguna manera prueba una posible adhesión ideológica al peronismo, estos contactos se repetirían en los años siguientes; el propio Balseiro bromeaba respecto a ellos en un intercambio epistolar con Beck, reconstruido por López y Badino (2000):

El 25 de julio [de 1951], Balseiro le escribe a Beck: "supe extra oficialmente que en La Plata me van a dar la licencia. No por la buena voluntad de Pascali sino por los buenos oficios del Diablo, a quien vendí un pedazo de mi alma'. Beck contesta: 'el diablo quien arregló su licencia en La Plata es un pobre diablo... actualmente disfrazado de director nacional de Investigaciones Técnicas" (pp. 139-140).

6 El Proyecto Huemul, a cargo del austríaco Ronald Richter, tuvo como objetivo el desarrollo de una técnica para alcanzar la fusión atómica controlada, una fuente de energía prácticamente inagotable, hasta el día de hoy solo hipotética. En negociaciones que comenzaron en 1948, Richter había logrado convencer a Perón de que poseía los conocimientos necesarios para alcanzar dicho objetivo y recibió a cambio un presupuesto incomparable a cualquier otra iniciativa científico-tecnológica de la época, el control de una isla en el lago Nahuel Huapi, frente a la ciudad de San Carlos de Bariloche, y amplios márgenes de autonomía en sus supuestos trabajos de investigación. Finalmente, el propio gobierno peronista reconoció el fraude del que había sido víctima.

92 Si Somos Americanos. Revista de Estudios Transfronterizos 
En su carta, Balseiro hacía referencia al pedido de licencia en la UNLP para poder así continuar sus estudios en Manchester: el ingeniero Carlos Pascali era, justamente, el presidente de la Universidad en el momento. El "pobre diablo" al que Beck hace referencia es el coronel (retirado) Enrique González, amigo personal de Perón, director de la Dirección Nacional de Investigaciones Técnicas (futura DINCyT) y a la vez, secretario de la CNICyT, que presionó al presidente de la UNLP para que aprobara la licencia. Resultado del mismo contacto fue el decreto de contratación de Balseiro como asesor de la Comisión de Asuntos Técnicos, firmado por el propio Perón, que vendría a solucionar las estrecheces económicas de su beca en Inglaterra. A cambio, durante 1950 y 1951, Balseiro mantuvo correspondencia con Francisco de Lucca Muro, un funcionario del Ministerio de Asuntos Técnicos (MAT), quien le pidió información sobre la organización de las agencias de promoción científica de Inglaterra y de Brasil (supuesta escala de Balseiro antes de regresar a la Argentina), donde avanzaban los proyectos de institucionalización de una dirección centralizada para las investigaciones científicas y técnicas. El viaje, sin embargo, debió ser suspendido cuando en Argentina se decidió la organización de la Comisión Investigadora que viajaría a Huemul (López y Badino, 2000, pp. 137 y 143).

Desde su llegada a Manchester, Balseiro se había demostrado diplomático y moderado en sus opiniones sobre la situación en Argentina. Algunos de sus colegas recuerdan que "evitaba cualquier aseveración demasiado fuerte que lo mostrara contrario a Perón" (López y Badino, 2000, p. 124), inclusive cuando el anuncio de Richter hizo tristemente célebre los proyectos nucleares del país entre la comunidad científica extranjera. El informe que presentó luego de visitar Huemul, no se reserva ni disimula ninguna crítica: su evaluación resalta lo inexacto de las teorías del físico austríaco, la ausencia absoluta de resultados verificables para sus experimentos y aun la carencia de un mínimo nivel académico del "sabio", que el mismo Perón hacía poco tiempo había premiado con la medalla peronista. Su opinión resultó fundamental para la decisión de conformar una segunda comisión y, finalmente, cancelar el Proyecto Huemul. Es decir, no hay nada en el comportamiento de Balseiro que nos permita inferir que la colaboración con el MAT o la CNICyT implicaran algún tipo de subordinación a la política partidista.

Más bien, lo que se encuentra presente aquí es una aproximación distinta a las relaciones entre Estado y mundo académico. Una primera diferencia con una experiencia como la de Gaviola fue el destino de su viaje de perfeccionamiento al exterior: cerradas las puertas de las universidades norteamericanas, Balseiro vivió en Manchester aquella cultura académica anglo-estadounidense que se citó anteriormente, en la que el rol protagónico del Estado era indiscutible, también en lo que a políticas científicas se refería. 
Balseiro no se relacionó directamente con tantos referentes internacionales de la física moderna como lo hizo Gaviola, pero la red que construyó puede ser considerada más amplia al menos en un sentido: porque incluyó a nuevos actores involucrados en la actividad científica, pero que no necesariamente provenían de los claustros universitarios. Políticos y técnicos de las nacientes instituciones científicas no solo lo ayudaron en su perfeccionamiento en el exterior y a insertarse en lo que comenzaba a perfilarse como un incipiente sistema nacional de ciencia y tecnología, sino que, además, se convirtieron en mediadores fundamentales para el sostenimiento de sus proyectos y gestiones institucionales.

Entre 1952 y 1955, Balseiro repartió su tiempo entre la Universidad de Buenos Aires (UBA) y la Comisión Nacional de Energía Atómica (CNEA), logrando que esta canalizara aportes económicos para paliar la crítica situación de desinversión en aquella (Gaviola había rechazado la oferta de sumarse a la nueva institución, a cargo de la Marina, por considerar que el espíritu de la disciplina militar no era compatible con la investigación científica). La CNEA le ofreció a Balseiro, además, la oportunidad de organizar dos escuelas de verano en Bariloche, que tuvieron lugar en enero y febrero de 1954 y 1955. Luego de la cancelación del Proyecto Huemul, el grupo que inspeccionó y relevó las instalaciones y equipos determinó que la isla debía ser abandonada y todo su material trasladado a los antiguos barracones militares en la costa del lago, donde ya se levantaban algunas casas y un laboratorio. Su idea, entonces, era aprovechar la infraestructura, equipos y recursos abandonados allí para la capacitación de científicos argentinos y de la región (en 1955 hubo un curso especialmente apuntado a profesores de Bolivia, Chile y Perú).

Ya en 1953, Balseiro había concebido la posibilidad de una escuela de física permanente en Bariloche, y había logrado convencer a Gaviola para que pusiera su nombre y prestigio internacional al frente de la misma. Pero la gestión de una institución semejante implicó negociaciones permanentes y algunas concesiones al poder político que Gaviola nunca hubiera aceptado. De hecho, él se separó del proyecto por no estar de acuerdo en la forma en que se organizarían los cursos del futuro Instituto de Física de Bariloche (IFB), retrasando así su fundación en dos años. En tanto había sido el encargado de organizar la última escuela de verano y el principal impulsor del proyecto, al retomarse la organización del nuevo instituto, la dirección del IFB recayó sobre Balseiro.

Mientras que simples diferencias en cuanto a la organización curricular habían sido suficientes para alejar a Gaviola del proyecto, Balseiro encontró la manera de convivir y negociar con el poder político. Mientras se organizaba y comenzaba a funcionar 
el IFB, por ejemplo, el nombramiento de dos profesores acusados de opositores fue objetado por los servicios de inteligencia de la Policía Federal; Balseiro intercedió por ambos y logró que uno de ellos pudiera mantener su cargo en la UBA, pero ninguno pudo quedarse en Bariloche. Mucho menos que eso habría bastado para que Gaviola presentara su renuncia, pero bajo la dirección de Balseiro, los trabajos en el Instituto siguieron adelante. Aún luego del golpe de Estado de septiembre de 1955, cuando los estudiantes se movilizaron para quitar los cuadros de Juan y Eva Perón que presidían las instalaciones, él ordenó que volvieran a colgarse hasta que la situación política terminara de definirse, asegurando la supervivencia de una institución aún incipiente (López y Badino, 2000, pp. 186 y 190).

Lo que aquí he tratado de resaltar no es una coincidencia política con el peronismo, sino más bien una tendencia hacia la despolitización del quehacer científico, propia de la época y de una nueva cultura académica de raíces norteamericanas. Una última comparación entre las figuras recuperadas en este trabajo, puede servir de ejemplo del cambio que estaba ocurriendo en el período.

Mientras duró su estadía en Alemania, Gaviola participó de varias reuniones del Partido Socialista Alemán, y a su regreso a la Argentina estuvo afiliado al PS local durante dos años, tiempo en el cual mantuvo numerosas reuniones y una fluida correspondencia con Alicia Moreau de Justo. Como destaca Bunge (2001, p. XIV), el contacto, en Berlín, con el pensamiento de Hans Reichenbach y Philip Frank había influido fuertemente sobre su visión respecto a la filosofía de las ciencias y al rol que las mismas jugaban y jugarían en el devenir de la historia contemporánea. En sus numerosas intervenciones públicas quedarían manifiestas tales influencias: las ciencias eran vistas, desde esta perspectiva, como herramientas para la planificación racional de una vida social superadora de las prácticas oscurantistas y reaccionarias.

El contraste con la figura de Balseiro no es solo producto de diferentes personalidades individuales, sino de una concepción distinta sobre la labor científica. En 1955, Walter Baltensperger, un antiguo colega de Manchester de visita en la Argentina, le preguntaba a Balseiro por las perspectivas a futuro de sus investigaciones en el país, a lo que él le respondió que "tenía la esperanza de que pudiera crearse un laboratorio en Bariloche, que estaría lo suficientemente alejado de los acontecimientos políticos y de esa manera la investigación sería posible" (López y Badino, 2000, p. 125). Esto es lo que Reisch llama "la torre de marfil de la posguerra": el resultado de un largo proceso de selección al que han sobrevivido solo aquellos científicos que aceptaron, a cambio de generosos fondos públicos volcados a la investigación, trabajar en enclaves aislados de (y pasivos frente 
a) lo político. En el caso de la ciudad de Bariloche en 1955, por otra parte, la noción de "aislamiento" estaba lejos de ser exagerada7.

\section{Conclusiones}

Este trabajo se ha propuesto como objetivo, analizar las consecuencias que sobre la comunidad académica local tuvo el corrimiento del centro científico internacional desde Alemania hacia los Estados Unidos. Para ello, se han analizado las trayectorias académicas de dos figuras centrales de la física argentina de mediados del siglo XX, pero más análisis de este tipo serían necesarios antes de generalizar conclusiones para el conjunto del mundo académico de la época. A pesar de lo acotado de su alcance, las hipótesis extraídas de este trabajo se ajustan a los casos estudiados de forma comparativa y podrían servir como clave de lectura para el análisis de otras trayectorias profesionales que las pongan a prueba.

El surgimiento de la cultura académica anglo-estadounidense como patrón internacional hegemónico luego de 1945, implicó un proceso de selección dentro de su población de científicos y académicos. Los criterios, según los cuales ciertos individuos "sobrevivieron" en el mundo académico y otros fueron (relativamente) marginados, responden a la capacidad de cada uno para adaptarse al nuevo contexto intelectual y socioeconómico. Con el fin de la guerra, el Estado se había consolidado (en Argentina y el mundo) como el principal impulsor, garante y coordinador de las investigaciones científicas, imponiendo como prioridades la vinculación tecnológica con proyectos específicos de desarrollo industrial y defensa nacional. En forma paralela, la intervención pública del científico, en cuanto intelectual de tipo clásico, daba paso al trabajo técnico para el Estado propio del experto.

Si algo prueba el caso de Gaviola, es que la capacidad para adaptarse a esta situación creada por la nueva hegemonía norteamericana responde, en primer término, a una determinación de tipo cultural. En este sentido, no es que Gaviola careciera de relaciones, contactos y un capital intelectual creado en relación a la academia norteamericana, sino más bien, que su formación profesional se había realizado bajo los parámetros alemanes de la erudición y la autonomía científica.

Entrevistado por el autor, Daniel Bes, destacado físico argentino contemporáneo de Balseiro, aseguraba que su rechazo, como el de otros, a la oferta de sumarse al plantel docente del IFB, se debió, únicamente, a ese mismo aislamiento, que se hacía aún más profundo durante el invierno. 
La nueva cultura académica dominante a nivel mundial impuso, además, una despolitización de la investigación científica. El peronismo imprimió características específicas a este proceso en la Argentina, pero no necesariamente contrarias a la tendencia a nivel internacional. Si bien es cierto que en las universidades nacionales se exigió de los profesores su afiliación al Partido Peronista, en las nuevas instituciones de ciencia y tecnología que acapararon el presupuesto de investigación a partir de 1950, tal exigencia nunca existió. Y si el catolicismo de José Balseiro fue, seguramente, más compatible con la construcción política del primer peronismo que el socialismo de clave internacionalista de Gaviola, probablemente lo mismo podría haber sido dicho de encontrarse estos científicos en la universidad norteamericana de principios de los 50.

El éxito de Balseiro en sus relaciones con el Estado peronista se explica, más que por una coincidencia político-ideológica, por la construcción de una red de contactos que excedía lo exclusivamente académico para incluir a representantes de la burocracia estatal, aceptados como interlocutores necesarios para la gestión de instituciones y proyectos científicos. Sin duda, Gaviola y Balseiro pertenecen a dos generaciones distintas, pero no son difusos "climas de época" los que separan ambas experiencias, sino la forma de incorporación de cada uno en las redes académicas transnacionales que les son contemporáneas.

\section{Referencias}

Bellocopitow, E. (2003). De cómo Berlín perdió la guerra. El arca 53 (11).

Bernaola, O. (2001). Enrique Gaviola y el observatorio Astronómico de Córdoba. Su impacto en el desarrollo de la ciencia argentina. Buenos Aires, Argentina: Ediciones Saber y Tiempo.

Bloor, D. (1998). Conocimiento e imaginario social. Barcelona, España: Editorial Gedisa.

Bunge, M. (2003). Prólogo 2. En O. Bernaola, Enrique Gaviola y el Observatorio Astronómico de Córdoba. Su impacto en el desarrollo de la ciencia argentina (pp. XIII-XXI). Buenos Aires, Argentina: Ediciones Saber y Tiempo.

Comastri, H. (2012). Estrategias argentinas frente al boicot norteamericano en ciencia y tecnología (1946-1955). Huellas de Estados Unidos. Estudios, perspectivas y debates desde América Latina 3, 129-147. 
De Asúa, M., y Hurtado, D. (2006). Imágenes de Einstein. Relatividad y cultura en la Argentina. Buenos Aires, Argentina: Eudeba.

Feld, A., y Hurtado, D. (2010). La revista Mundo Atómico y la "Nueva Argentina" científica (1950-1955). En C. Panella, y G. Korn (eds.), Ideas y debates para la Nueva Argentina. Revistas culturales y políticas del peronismo (1946-1955) (pp. 199-228). Buenos Aires, Argentina: Editorial de la Universidad Nacional de La Plata.

Gaviola, E. (1931). Reforma de la universidad Argentina y Breviario del Reformista. Buenos Aires, Argentina: Editorial. L.J. Rosso.

Gaviola, E. (1965). Biblioteca Leo Falicov, Instituto Balseiro, Bariloche, Archivo Gaviola (AG) C11- 16.

Harwood, J. (2006). Diferencias nacionales en la cultura académica: ciencia en Alemania y Estados Unidos entre las dos guerras mundiales. En C. Charle, J. Schriewer y P. Wagner (comps.), Redes intelectuales transnacionales. Formas de conocimiento académico y búsqueda de identidades culturales (pp. 46-71). Barcelona, España: Ediciones Pomares.

López, A., y Badino, N. (2000). J.A. Balseiro: crónica de una ilusión. Buenos Aires, Argentina: Fondo de Cultura Económica.

Mariscotti, M. (2004). El secreto atómico de Huemul. Crónica del origen de la energía atómica en la Argentina. Buenos Aires, Argentina: Estudio Sigma.

Moulin, A. (2006). La red internacional de trabajo del Instituto Pasteur: innovaciones científicas y tropismos franceses. En C. Charle, J. Schriewer, y P. Wagner (comps.), Redes intelectuales transnacionales. Formas de conocimiento académico y búsqueda de identidades culturales (pp. 119-146). Barcelona, España: Ediciones Pomares.

Neiburg, F., y Plotkin, M. (comps.). (2004). Intelectuales y expertos. La constitución del conocimiento social en Argentina. Buenos Aires, Argentina: Editorial Paidós.

Ortiz, R. (1998). Otro territorio. Bogotá, Colombia: Convenio Andrés Bello.

Reisch, G. (2009). Cómo la Guerra Fría transformó la filosofía de la ciencia. Hacia las heladas laderas de la lógica. Quilmes, Argentina: Universidad Nacional de Quilmes.

98 Si Somos Americanos. Revista de Estudios Transfronterizos 
Stichweh, R. (2006). De la peregrinatio academica a los flujos internacionales contemporáneos de estudiantes: cultura nacional y diferenciación funcional como causas emergentes. En C. Charle, J. Schriewer y P. Wagner (comps.), Redes intelectuales transnacionales: formas de conocimiento académico y búsqueda de identidades culturales (pp. 269-284). Barcelona, España: Ediciones Pomares.

Weinberg, A. (1961). Impact of Large-Scale Science on the United States. Science 134, 161164. 